\title{
Treatment cost on Visceral Leishmaniasis: Case study in endemic districts of Nepal
}

Dharanidhar Baral

Shri Jagdishprasad Jhabarmal Tibrewala University, Jhunjhunu, Rajasthan, India

\section{Correspondence \\ Mr. Dharanidhar Baral, \\ Research Scholar, \\ Shri Jagdishprasad Jhabarmal \\ Tibrewala University, \\ Jhunjhunu, Rajasthan, India \\ Email: ddbara1@yahoo.com}

DOI: http://dx.doi.org/10.3126/ jcmsn.v12i2.15456

Article received: March $22^{\text {nd }} 2016$ Article accepted: April $22^{\text {nd }} 2016$

\begin{abstract}
Background \& Objectives: Approximately six million people are at risk of infection from Visceral Leishmaniasis (VL) in Eastern and middle plain region of Nepal. The disease affects the rural poor socio-economical community causing significant death among untreated patients (Per capita income of Nepal US \$ 400.00). An effort was made to estimate treatment cost on clinically diagnosed VL patients in three VL endemic districts of Eastern development region of Nepal. Materials \& Methods: During one and half year period in 2012/2013, approximately 500 cases were diagnosed as VL from three district hospitals; two zonal hospitals and one tertiary level hospital of Eastern Terai districts of Nepal. Total 172 cases were selected randomly from the three VL endemic districts of Eastern Nepal and interviewed at their homes. Results: On an average, cost for VL treatment during hospitalization was Nepali Rupees (NRS) $4032.67 \pm$ 313.47, where median (IQR) length of hospital stay was 17 (five to 35) days. The patients were diagnosed symptomatically as VL after $45 \pm 6$ days of feeling illness. The treatment cost of patient before diagnosis was NRS $2379.93 \pm 202.30$. Patient reached the treatment center after $17 \pm 2$ days of diagnosis and referral from community level. Total $83.7 \%$ patients came for follow-up after average $30 \pm 2$ days of discharge with an average expense of RS $360.34 \pm 49.88$. The death rate of VL patients during treatment and within one month of discharge was $7.6 \%$. It was found that the average funeral cost was NRs $9598.00 \pm 1259.00$. Conclusion: This study concludes that, average treatment cost for VL treatment during hospital stay was NRs 4032 and before treatment was around NRS 2380 and follow up cost was NRs 360. Early diagnosis and treatment in treatment center without significant delay can not only reduce the hospital stay and treatment cost, but also saves life of VL patients.

Key words: Kala azar; Treatment cost; Visceral Leishmaniasis
\end{abstract}

Citation: Baral D. Treatment cost on Visceral Leishmaniasis: Case study in endemic districts of Nepal. JCMS Nepal. 2016;12(2):60-5.

\section{INTRODUCTION}

Approximately six million people residing in Eastern districts of plain areas of Nepal are at risk of infection from VL. ${ }^{1,2}$ The national policy of Nepal defines the possible case of VL is "a person who visits or resides in VL endemic areas and having fever for more than two weeks with and without splenomegaly, malaria parasite negative in blood examination and not responding to standard treatment of anti-malaria drugs". 3 Therefore, community level health facility can refer a symptomatic VL patient after two weeks of his/her illness. ${ }^{1,3}$ In Nepal, studies have established that the disease affects the rural poor social economical community and cause significant death, in not timely treated cases. ${ }^{1-5}$ In Nepal, alpha cypermethrim insecticide is used for indoor residual spray (IRS) to control VL in VL reporting villages but there is neither any vaccine nor possible treatment for infections and symptomatic carriers without laboratory diagnosis. ${ }^{1,3,6}$ Organ aspiration and accurate examination of smears also require technical skills that are not uniformly available in rural areas of Nepal. ${ }^{1-3,5}$ Preventive measure can reduce VL morbidity and mortality, 1 and correct diagnosis and treatment prevent more than $90 \%$ deaths in community. ${ }^{1,7}$ Nepal is ranked as one of poorest country in the world and lack government health insurance policy; so any expenditure in health incur burden on economic condition of Nepalese citizen. So this study tried to analyze and estimate the treatment expenditure in various activities throughout the treatment of VL in Nepal. The primary aim of this study was to determine 
treatment cost on clinically diagnosed VL patients of endemic districts of Nepal. The study also aimed to correlate treatment cost and duration of treatment.

\section{MATERIALS AND METHODS}

Study area: The study was based in the household survey of VL discharged patients from districts, zonal and referral hospitals of typical disease-endemic regions of VL in Eastern Nepal. These districts are Sunsari, Saptari and Siraha situated in the plain foot hills of Himalayas and have the favorable environment for transmission of VL such as alluvial soil, high sub-soil water, a monthly mean maximum temperature below $37^{\circ} \mathrm{C}$, a monthly mean minimum temperature above $7.2^{\circ}$ $\mathrm{C}$, an annual rainfall $1,250 \mathrm{~mm}$, a mean annual relative humidity $70 \%$, abundant vegetation and an altitude $<600$ meters. The climate of the study areas is similar with no wide variation. These conditions are highly suitable for an abundance of sand flies facilitating perennial transmission of VL. Agriculture and its associated activities is the mainstay of the economy of these areas.

Study design: This was a cross-sectional study. The sample units were clinically and parasitological confirmed VL from districts, zonal and referral hospitals of Eastern Nepal.

Sample size and sampling: A total 500 cases diagnosed as VL from the eastern Nepal in the year April 2012 to August 2013 were the sample included in the study. District wise patient list was made and total 172 discharged patients were selected randomly. Patients were identified by rechecking their identification which was written during the time of admission at hospitals and interviewed at their homes in the field. Informed consent was obtained from all cases before including them into this study. The study was reviewed and approved by the Research Committee and Ethical Board of BPKIHS.

Tools and techniques of data collection: Pre tested structured questionnaire was used to collect information regarding the socio demographic variables, illness of disease onset cost, cost during treatment, discharged and follow up as well as duration of treatment in various levels of facilities, of VL patients.

Data analysis: Collected data were decoded and scrutinized by investigator for accuracy and consistency. Data were entered in Microsoft Excel 2007 and converted it into Statistical Package for
Social Sciences 11.5 version (SPSS, Inc. Chicago, IL). Data were validated by logical and range checks by SPSS. Descriptive statistics were calculated to find out the expenditure of VL treatment. The correlation of treatment costs with hospital stay was interpreted by Pearson correlation. All the tests were considered significant if $\mathrm{p}$ value $<$ 0.05 .

\section{RESULTS}

The socio demographic variables like age group, educational status, religion, mother tongue, caste, family types and sex of decision maker in family were recorded (Table 1). The result revealed that all cases from three districts were similar in socio demographic characteristics. The findings revealed that most of the VL patients belonged to low socioeconomical strata of the community. About half of the patients were in the age group 41 to 60 years and almost $70 \%$ of the patients were illiterate. Maximum patients were Hindu by religion. About two third of patients were Maithali speaking and about one third were Tharu speaking. More than one third of patients were from Terai Janajati (majority Tharus).

The sleeping habit of VL cases before coming for treatment was also recorded (Table 2). Almost all of the patients $(94.19 \%)$ were sleeping on ground floor and almost half had the habit of sleeping on muddy ground floor. More than one fourth never used bed nets, other quarter used only during summer and approximately half of them always used bed or cot regularly while sleeping. Only one third patients used double-bed net before coming for treatment. More than $90 \%$ patients had used very big-hole net before treatment.

For the cost estimation, we tried to cover all type of costs which was reported by the VL cases and his/ her family members and number of days lost due to disease was calculated (Table 3).

The average annual income of KA patients' family was found to be Rs 12,321 (US \$ 116.23) and there was not much variation between the districts. The average cost incurred on VL treatment during hospital stay was Rs. $4032.67 \pm 1034.14$, which is nearly one third of the annual income of the patients' family. The item wise cost on VL patients was found as follows: cost before diagnosis was Rs $2379.94 \pm 265.31$, Doctor/Institutional registration fee Rs. $60 \pm 20$, cost of drugs during hospitalization was Rs $200.15 \pm 24.12$, Laboratory Investigation cost during hospitalization was Rs $290.00 \pm 45.34$, 
Table 1: Socio demographic characteristics of cases by districts

\begin{tabular}{llccccc} 
Characteristics & Category & Saptari & Siraha & Sunsari & Total & Percentage \\
& $\leq 20$ & 0 & 1 & 0 & 1 & 0.58 \\
Age group in years & $21-40$ & 21 & 33 & 15 & 69 & 40.11 \\
& $41-60$ & 24 & 40 & 19 & 83 & 48.25 \\
& $\geq 61$ & 6 & 9 & 4 & 19 & 11.05 \\
\hline \multirow{3}{*}{ Educational Status } & Literate & 19 & 22 & 12 & 53 & 30.81 \\
& Illiterate & 32 & 61 & 26 & 119 & 69.19 \\
\hline Religion & Hindu & 50 & 76 & 32 & 158 & 91.86 \\
& Others & 1 & 7 & 6 & 14 & 8.14 \\
Mother tongue & Maithali & 29 & 64 & 17 & 110 & 63.95 \\
& Tharu & 20 & 15 & 17 & 52 & 30.23 \\
& Others & 2 & 4 & 4 & 10 & 5.82 \\
Caste & Terai Janajati & 27 & 18 & 21 & 66 & 38.37 \\
& Terai major caste & 13 & 32 & 12 & 57 & 33.14 \\
& Terai dalit & 10 & 29 & 3 & 42 & 24.42 \\
Type of family & Others & 1 & 4 & 2 & 7 & 4.07 \\
\hline $\begin{array}{l}\text { Sex of the decision } \\
\text { making in household } \\
\text { head }\end{array}$ & Nuclear & 32 & 44 & 23 & 99 & 57.56 \\
Total & Joint & 19 & 39 & 15 & 73 & 42.44 \\
\hline
\end{tabular}

Table 2: Sleeping habit of VL patients before illness

\begin{tabular}{|llccccc|}
\hline \multicolumn{1}{c}{ Sleeping Habit } & Category & Saptari & Siraha & Sunsari & Total & Percentage \\
\hline Sleeping floor & Ground & 52 & 81 & 30 & 162 & 94.19 \\
& First & 0 & 2 & 8 & 10 & 5.81 \\
\hline \multirow{3}{*}{ Sleeping place } & Ground & 23 & 37 & 17 & 77 & 44.77 \\
& Bed & 28 & 46 & 21 & 95 & 55.23 \\
Bed Net use & Always & 18 & 31 & 27 & 76 & 44.19 \\
& Summer only & 21 & 24 & 4 & 49 & 28.49 \\
\multirow{3}{*}{ Bed Net size } & Never & 12 & 28 & 7 & 47 & 27.32 \\
& Single & 23 & 26 & 2 & 51 & 40.80 \\
\multirow{3}{*}{ Cloth of bed net in term } \\
of area of square & Double & 12 & 17 & 10 & 39 & 31.20 \\
& Both & 4 & 12 & 19 & 35 & 28.00 \\
& Big-hole & 35 & 48 & 31 & 114 & 91.20 \\
& Small-hole & 2 & 4 & 0 & 6 & 4.80 \\
& Both & 2 & 3 & 0 & 5 & 4.00
\end{tabular}

Hospital admission service cost Rs $65 \pm 10$ and cost of drugs after discharge was found to be Rs 475.00 \pm 115.00 . It was also found that on an average of Rs. $3652.90 \pm 1534.11$ was spent on the cost related to food, travel and attendants' expenditure. Cost for follow-up was Rs $360.34 \pm 49.14$. On average, patients got VL treatment at district hospital after $45 \pm 16$ days of the disease. They got treatment at district level on an average of $17 \pm 8$ days after being referred from the community level. The average length of stay was $16 \pm 7$ days at hospital. Out of 172 VL cases only $83.7 \%$ of patients came for follow-up after $30 \pm 5$ days from the date of discharge. Out of the total cost Rs $7247.95 \pm$ 3672.90 after diagnosis, $75.04 \%$ cost was spent on travel, accommodation, food, and patients' attendant expenditure. It was also found that the total cost were significantly varying in the three 
Table 3: Unit cost of VL patients in different items by districts

\begin{tabular}{|c|c|c|c|c|}
\hline \multirow[b]{2}{*}{ Cost and days spent during treatment } & \multicolumn{3}{|c|}{ District } & \multirow{2}{*}{$\begin{array}{l}\text { Total } \\
\text { Mean }\end{array}$} \\
\hline & Saptari & Siraha & Sunsari & \\
\hline $\begin{array}{l}\text { Average annual income of KA patients' family in } \\
\text { NRs }\end{array}$ & 12529 & 12106 & 12511 & 12321 \\
\hline $\begin{array}{l}\text { Average treatment cost before KA diagnosis at } \\
\text { community level in NRs }\end{array}$ & 2652.94 & 1831.93 & 3210.53 & 2379.94 \\
\hline $\begin{array}{l}\text { Average cost spent on drugs during hospitalization } \\
\text { in NRs }\end{array}$ & 178.43 & 193.07 & 244.7 & 200.15 \\
\hline $\begin{array}{l}\text { Average investigation cost during hospitalization in } \\
\text { NRs }\end{array}$ & 600.00 & 120.00 & 250.00 & 290.00 \\
\hline Registration fee (OPD)in NRs & 50.00 & 50.00 & 80.00 & 60.00 \\
\hline Hospital service cost (Admission)in NRs & 50.00 & 40.00 & 150.00 & 65.00 \\
\hline $\begin{array}{l}\text { Average overall hospital cost (drugs }+ \text { investigation } \\
+ \text { registration }+ \text { admission) during hospitalization in } \\
\text { NRs }\end{array}$ & 750.00 & 275.00 & 550.00 & 475.00 \\
\hline Other costs (attendant, food, travel) in NRs & 5158.51 & 3884 & 1285 & 3652.9 \\
\hline $\begin{array}{l}\text { Total cost during hospitalization (overall hospital } \\
\text { cost }+ \text { other cost) in NRs }\end{array}$ & 5493.73 & 4143 & 1832 & 4032.67 \\
\hline Drugs cost after discharged in NRs & 600.00 & 350.00 & 550.00 & 475.00 \\
\hline Cost of follow-up in NRs & 515.00 & 290.00 & 300.00 & 360.34 \\
\hline Average funeral cost $(n=13)$ in NRs & & & & 9598.00 \\
\hline $\begin{array}{l}\text { Average number of days taken to contact health } \\
\text { personal after illness }\end{array}$ & 46 & 49 & 35 & 45 \\
\hline $\begin{array}{l}\text { Average number of days taken to attended referral } \\
\text { centers from the community level }\end{array}$ & 23 & 19 & 6 & 17 \\
\hline Average days of hospitalization & 17 & 18 & 13 & 16 \\
\hline Follow-up after( in days) & 22 & 27 & 45 & 30 \\
\hline
\end{tabular}

Table 4: Correlation between days of hospitalization with various variables

\begin{tabular}{lcc}
\multicolumn{1}{c}{ Variables } & \multicolumn{2}{c}{$\begin{array}{c}\text { Days of } \\
\text { hospitalization }\end{array}$} \\
& $\begin{array}{c}\mathrm{r}- \\
\text { value }\end{array}$ & $\begin{array}{c}\mathrm{p}- \\
\text { value }\end{array}$ \\
\hline Total treatment cost & 0.715 & 0.031 \\
$\begin{array}{l}\text { Days to contact health } \\
\text { personal after illness }\end{array}$ & 0.779 & 0.019 \\
$\begin{array}{l}\text { Days to reach treatment and } \\
\text { diagnosis center after referral }\end{array}$ & 0.891 & 0.024 \\
\hline
\end{tabular}

districts $(\mathrm{p}<0.001)$.

The correlation analysis in table 4 shows that the days of hospitalization correlated with the total treatment cost incurred during treatment process of Kala-azar $(\mathrm{r}=0,715, \mathrm{P}<0.05)$. Similarly the days needed to contact health personnel after being ill $(\mathrm{r}=0.779, \mathrm{P}<0.05)$ and days to reach the proper treatment center after referral $(\mathrm{r}=0.891, \mathrm{P}<0.05)$ were also significantly correlated with number days of hospital stay.

\section{DISCUSSION}

According to the national policy, the treatment cost of VL cases is $100 \%$ free. Delay in case detection and treatment of VL is one of the main problems in Nepal. ${ }^{1-4,7-9}$ The reason for this delay could be because of very poor people living in the VL endemic area. ${ }^{8,9}$ Initially all cases of VL spend their money in medical pharmacy/shops for sub standard investigation. ${ }^{1}$ So the village level health systems hardly detect and refer the cases of VL to the 
appropriate treatment centers (district hospitals). As per national guideline, a kala azar case needs to be treated in less than two weeks, ${ }^{3}$ but our findings showed that the time taken between onset of the disease and treatment is more than two months. So the delay in treatment not only increases the cost of treatment but also takes longer time in hospital stay1 which was also evident in our study. The average length of hospital stay in kala azar treatment was 17 days, which was longer as compared to other diseases. ${ }^{1,3,9,10}$ There was statistically significant positive correlation between hospitalization days and total treatment cost $(\mathrm{r}=$ 0.715 and $\mathrm{p}=0.031)$. The longer duration of hospital stay would incur higher the treatment cost, thus we can argue that reducing the length of hospitalization days can reduce treatment cost (direct and indirect cost). Although national policy regarding treatment of Kala-azar is free in Nepal, ${ }^{2,3,7}$ but majority of the cost is incurred by indirect costs and investigations which is evident in this study where more than $75.04 \%$ expenditure was for traveling, food and investigation. Various studies done on Kala-azar reveal that the extra expenses in VL treatment and loss of income due to no-work days of patients and their attendants has negative impact on the low earning families. $1,5,7,8$ Studies have shown Kala-azar is a serious public health problem due to reason of not having enough community level hospital for diagnosis in the endemic region. ${ }^{1-13}$ Poor socio demographic factors in the endemic areas has remained as the major factor for the delay in treatment after referral from community. ${ }^{11,14,15}$ The nature of disease can make uncertainty to diagnose by untrained health staffs of community which exacerbates condition of sickness and becomes fatal if untreated. ${ }^{1,7,9}$ Very less number of community health workers involved in VL control program was found as the major constraints for timely referral of VL cases. ${ }^{2}$

\section{CONCLUSION}

The expenditure on treatment of disease kala azar still remains high for developing countries like Nepal though government has free treatment policy for this illness. We have little information to determine the expenses on different items over an extended period of time. So with limited information, this study provides the treatment expenditure on infectious disease and its relation with hospital stay among the poor households in Eastern Nepal. This study suggests that the investment in outreach facilities for early detection of VL patients in community may reduce hospital stay thereby reducing treatment cost of the disease.

\section{Acknowledgement}

I would like to thank District Public Health Officer, Medical Superintendents and Chief District Officers of Saptari, Siraha and Sunsari for their kind cooperation in data collection and permission for visiting districts despite of critical political situation of Nepal. I would like to express sincere gratitude to the Superintendents of Koshi, Sagarmatha zonal hospital and Hospital Director of BPKIHS for their kind cooperation during data collection. We remain indebted forever to all patients and their attendants who despite their deep grievances gave their fill consents and support to be included as study subjects for my study.

\section{REFERENCES}

1. Koirala S, Parija C. Kala-azar epidemiology, diagnosis and control in Nepal. B.P.Koirala Institute of Health Sciences; 1998. PMID:PMC2305780.

2. Department of Health Service. Annual Report 2009. Kathmandu; 2009. p. 145-9.

3. World Health Organization/South East Asia Regional Office. Regional strategic framework for elimination of kala-azar from the south-east Asia region (2005-2015). In: WHO Project No: IND CRD 714. New Delhi; 2005. p. 110.

4. BP S, NMa M, SRa A, JRb A, ABc J, Pd W, et al. Socioeconomic Determinants of Kala-azar in Nepal. JnhrcComNp [Internet]. 2004;2(1):58-65. Available from: http://www.jnhrc.com.np/files/2004/ vol2_number1_april2004/8.pdf

5. Bista M. National overview of kala-azar in Nepal. In: Kala -azar in Nepal: Principles, Practice and Public Health Perspectives. Kathmandu; 1998.

6. Mills A. The economic evaluation of malaria control technologies: the case of Nepal. Soc Sci Med. (34):96572. DOI: 10.1016/0277-9536(92)90127-c.

7. Epidemiology and Disease Control Division. The annual internal assessment of malaria and kala-azar control activities 2004, 2005 and 2006. Kathmandu; 2007. ; p. 2937

8. Mondal D, Singh SP, Kumar N, Joshi A, Sundar S, Das P, et al. Visceral leishmaniasis elimination programme in India, Bangladesh, and Nepal: reshaping the case finding/ case management strategy. PLoS Negl Trop Dis [Internet]. 2009 Jan [cited 2016 Apr 20];3(1):e355. Available from: http://www.pubmedcentral.nih.gov/articlerender.fcgi? artid $=2607537 \&$ tool $=$ pmcentrez\&rendertype $=$ abstract

9. Rijal S, Uranw S, Chappuis F, Picado A, Khanal B, Paudel IS, et al. Epidemiology of Leishmania donovani infection in high-transmission foci in Nepal. Trop Med Int Health [Internet]. $2010 \mathrm{Jul}$ [cited $2016 \mathrm{Apr}$ 20];15 Suppl 2:21-8. Available from: http://www.ncbi.nlm.nih.gov/ pubmed/20487421 
10. MoH. National Workshop on Prevention and Control of Vector Borne Diseases in Nepal. Report and Recommendations. Kathmandu: Epidemiology and Control Division, Department of Health Services; 2002.

11. Prasai DP. Cost and performance analysis of kala-azar case management. J Nepal Heal Res Counc. 2003;1:54-8.

12. Sarnoff R, Desai J, Desjeux P, Mittal A, Topno R, Siddiqui NA, et al. The economic impact of visceral leishmaniasis on rural households in one endemic district of Bihar, India. Trop Med Int Health [Internet]. $2010 \mathrm{Jul}$ [cited 2016 Apr 20];15 Suppl 2:42-9. Available from: http://www.ncbi.nlm.nih.gov/pubmed/20487423

13. Pokharel S, Joshi A. Is detecting Visceral leishmaniasis (Kala-azar) cases through existing control program costeffective and early in Nepal? J Nepal Heal Res Counc [Internet]. 2003 [cited 2016 Apr 20];1(3):9-16. Available from: http://e-library.nhrc.org.np/nhrc/cgi-bin/library.cgi? $\mathrm{e}=\mathrm{d}-01000-00$---off-0bibliogr--00-1----0-10-0---0---0direct -10----4------0-11--11-en-50---20-about---00-3-1-00-00--4 --0--0-0-11-10-0utfZz-8$00 \& \mathrm{cl}=\mathrm{CL} 4.4 \& \mathrm{~d}=\mathrm{HASH} 3 \mathrm{e} 1 \mathrm{a} 587 \mathrm{dd} 3 \mathrm{c} 8 \mathrm{bdcb} 63 \mathrm{~b} 4 \mathrm{~b} 4 \mathrm{~s} 437 \&$ $\mathrm{x}=1$

14. Khatiwada Y, Sharma S. Country Study Report 2002. Kathmandu; Institute for Integrated Development Studies (IIDS) 2002. p. 1-12

15. Central Bureau of Statistics Government of Nepal. Nepal Living Standard Survey 2003-04. Kathmandu; 2004. p. 1 115 